\title{
SPOC, FUTURE OF MLEARNING AND LANGUAGE LEARNING?
}

\author{
Hamed Asgari and Georges Antoniadis \\ Laboratory LIDILEM \\ Université Grenoble Alpes, France
}

\begin{abstract}
Mobile artifacts are objects that surround us increasingly in life. They give us the opportunity to engage in activities outside the traditional context and at our own pace. The objective of this article is the realization of the software on mobile artifacts for computer-assisted language learning (CALL) using the concept of SPOC (Small Private Online Course) for learning FLE (in French Français langue étrangère ${ }^{1}$ ).
\end{abstract}

\section{KEYWORDS}

SPOC, NLP, MIRTO, Mlearning, SPOC+, FLE

\section{INTRODUCTION}

Purpose of this study is to provide a complete description of a French language learning system based on SPOC (Small Private Online Course) integrating NLP (Natural Language Processing) tools and the MIRTO project (in French Multi-apprentissages Interactifs par des Recherches sur des Textes et l'Oral ${ }^{2}$ ) on mobile artifacts with a personalized follow-up procedure for each learner. Currently, a large number of SPOC educational theories and practices have been implemented (Fox and Patterson, 2013), such as the software engineering program at the University of California at Berkeley, the copyright course at Harvard Law School, the Python programming language course at MIT. China has also launched a pilot project of SPOC teaching activities, such as the first SPOC physics courses at Tsinghua University, circuit theory courses at Nanjing University and C language programming courses at the University of Zhejiang. Xuetang Online also created the SPOC platform for English courses. However, these SPOC pedagogical practices are not widely used because they are found only in renowned universities ( $\mathrm{Li}$ et al., 2019). The emergence of SPOC becomes an innovation of the "internet + " teaching model and constitutes a new form of information-based teaching. At the same time, teachers need to have a good understanding of the learners who choose the course, which can strengthen the management and supervision of learners, making SPOC an effective tool to improve teaching (Chen, 2019). Research on SPOC also shows that SPOC is more attractive than traditional classrooms. It stimulates learners' interest in learning and stimulates their participation (Chen, 2019). In the teaching process of SPOC, depending on the course curriculum, tutor publishes the instructional video and organizes homework assignments. Depending on the length of the course, learners can watch their personalized video, homework and online discussions (Lei, 2019). According to the literature, no scientific work has been done which addressed the use of SPOC in language learning with the integration of NLP tools for mobile artifacts.

\section{CONTEXTUALIZATION}

Teaching and learning are two words that are born from the birth of the human being. Since the creation of humanity, we are in the phase of either teaching or learning. According to Mike Sharples (Sharples, 2002),

\footnotetext{
${ }^{1}$ French as a foreign language

${ }^{2}$ Muti-Learning Interactive through Text and Oral Research
} 
the mobile learning movement, also called mlearning, emerged in the 1970s invented by Alan Kay with Dynabook. However, there is no consensus on the definition of mobile learning.

Recently, there are multiple definitions for mlearning; "any sort of learning that happens when the learner is not fixed predetermined location or learning that happens when the learner takes advantage of the learning opportunities offered by mobile technologies" (Vavoula et al., 2004), "learning supported by mobiles device such as cellular (mobile) phones, portable computers, and personal audio player" (Rheingold, 2002) and "learning by means of wireless technological devices that can be pocketed and utilized wherever the learner's device can receive unbroken transmission signals" (Attewell and Savill-Smith, 2005).

The notion of mobility in all definitions is the only one that does not change; the tools used for mobile learning can be different and evolving over time. In this article, we are interested in the notion of mobility for both mobile artifacts, the aspect of distance and the use of telecommunication technologies.

We define smartphone as the new generation of mobile phone, which apart from the current functionalities of mobiles (camera, video, sound recording, GPS connection, ...) which able to communicate from almost anywhere, as long as it picks up the signal that access the internet and by installing third-party applications it can present new functionalities.

\subsection{SPOC}

With innovation in technology, the educational model is also developing and progressively new modes of teaching are emerging. Currently, traditional software-based education is changing due to poor effects, low efficiency and low quality of teaching. In traditional mode, a single teacher continues to teach in the classroom and learners complete assignments independently, thus due to the low capacity of independent learning. Learners' understanding of the program is not sufficient and learning effect is difficult to assess. Todays, courses need to move away from the traditional model of single-teacher teaching and use modern teaching tools and methods, as well as high-quality teaching and a wide range of learning content in a limited amount of time. Nowadays, with the advent of the information age, the new teaching model is emerging and the traditional offline course and online teaching are constantly being integrated and updated (Lei, 2019).

SPOC, Small Private Online Course, was created by Professor Armando Fox (Fox, 2013) from the American University of California at Berkeley (Chen, 2019) in 2013, also known as the "post-MOOC era"(Chen, 2019) MOOC is the acronym for the Massive Open Online Course.

The meaning of small in SPOC is the scope of the class, where the number of learners is controlled and is limited to a small group comparing to MOOC which hundreds of learners are participated in. The meaning of Private is that the courses are not public on a large scale and accessibility is defined for the courses and scope of the course is limited to specific number of learners. By taking advantage of these restrictions, we look forward to improve learning efficiency and course completion of the learners. SPOC's teaching method is a combination of online and offline courses (Lei, 2019).

SPOC has become a completely new way of teaching, combining the information age with new teaching resources. The "Small Private Online Course" has also revolutionized content and form (Li et al., 2019). SPOC brings different learning experience to learners ( $\mathrm{Li}$ et al., 2019).

The teaching mode of SPOC is the development of MOOC's mood. This means that SPOC's teaching mode not only compensates for the disadvantages of MOOC in teaching courses; but also places the teaching of offline communication within MOOC's teaching mode. SPOC allows teachers to intervene directly in the whole learning process of the learners (Lei, 2019).

\subsection{NLP and MIRTO}

Our work falls within the fields of Computer-assisted language learning (CALL), natural language processing (NLP), as part of the MIRTO project (Antoniadis, 2010) invented by Georges Antoniadis and the concept of SPOC, invented in 2013 by Professor Armando Fox (Fox, 2013) teaching at the University of California.

According to the research of Georges Antoniadis, the objective of the MIRTO project is the design of a multilingual system for teaching languages, using:

- The set of NLP software resulting from scientific research and laboratories.

- The diversity and richness of textual and oral corpora. 
- A set of NLP functions (NLP function is obtained from NLP software) (Antoniadis et al., 2005)

Our main objective is the definition, the conceptualization of the architecture and the elaboration of a system for the learning of French as a foreign language to the non-French speaker on mobile artifacts with the concept of SPOC that we have just described above. Used MIRTO's previous work to be able to integrate the automatic creation of exercises and their corrections into our solution with a morphological analyzer. MIRTO should be able to implement classic NLP functions within the platform to facilitate the conception, without prior computer skills, of didactic activities (Antoniadis et al., 2005). We will explain this functionality in more detail.

\subsection{Learning and Mobile Artifacts}

According to (Reynolds and Anderson, 2015) the rapid advances in information and communication technologies in recent years have created new opportunities for education. Now that most people have mobile devices, learning can be extended beyond the traditional classroom ( $\mathrm{Wu}, 2016)$. Based on the work of Abdous (Abdous et al., 2009) and $\mathrm{Wu}(\mathrm{Wu}, 2014)$ mobile technologies are reshaping learning and teaching by supporting, developing and enhancing course content, learning activities and student interactions with the instructor, peers, and learning content. The technologies help overcome many limitations and barriers in the traditional classroom, including a lack of opportunities for language use, individualized learning, feedback and interaction (Ahn and Lee, 2016) and can provide a seamless learning experience, i.e., learning anytime, anywhere (Liu and Chen, 2015).

According to Shadiev (Shadiev et al., 2017), in general, students have a positive perception of learning a language with a mobile phone and that the latter has positive effects on language proficiency. They also found that the most used technologies were smartphones and learners were more university students.

Our objective is the evolution of the MIRTO system by integrating mobile learning (mlearning) in order to obtain a system for learning the French language with a complete architecture.

The complete system is composed of different modules: user interface (administrator, teacher, and learner), activity generator, correction module, morphological analyzer, and feedback. This architecture must be possible to follow the evolutions and updates of the tools and mobile interfaces, also should be able to add new functions of NLP modules.

Now we have developed our solution, which is considering all the functional aspects of a complete system. Our solution is composed of a website, a web interface, and a mobile software. (figure1).

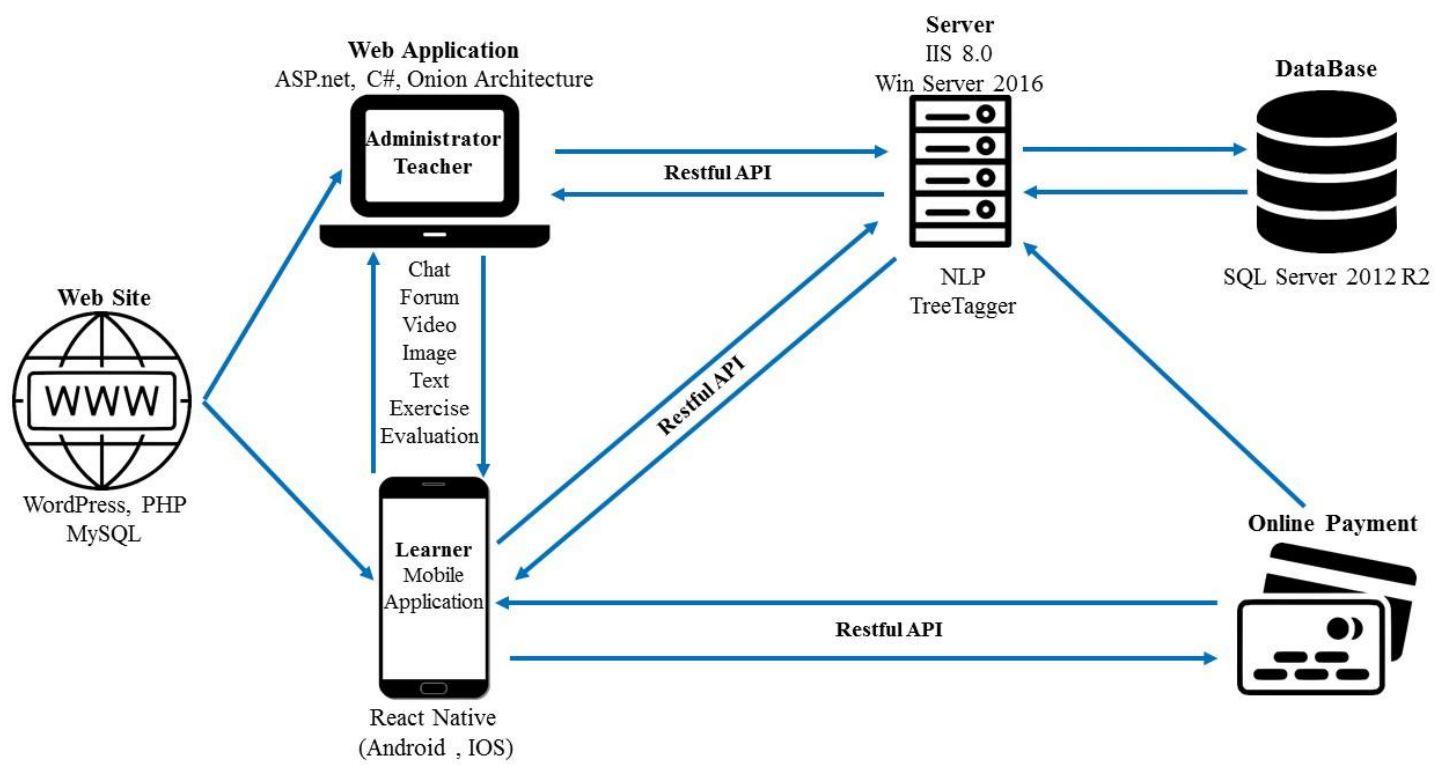

Figure 1. SPOC+ architecture 
For doing that, we need a reliable morphological analyzer, which is indispensable for automatically generating activities through our platform. For French processing, two analyzers that are mainly used by the NLP community: TreeTagger, developed by Helmet Schmid (Schmid, 1994) at the University of Stuttgart and Brill (Dejean et al., 2010). Both of them are open source, but only TreeTagger is available for Windows and it has the advantage of being multi-platform. According to the studies of Allauzen and Bonneau-Maynard (Allauzen and Bonneau-Maynard, 2008), the reliability rate of TreeTagger is $95.7 \%$ compared to Brill which is $94.6 \%$. With TreeTagger and those 33 labels, we can define and generate automatically MCQ exercises, text with holes, questions, and answers of grammar, conjugation, or spelling.

The website only used for the presentation of the application and our solution. The website made in PHP language with WordPress as the basic CMS. Collecting of colors and the design of our UI (User interface) were carefully considered. We chose blue for its soothing, calmness and relaxation (Singh, 2006) aspect (figure 2).

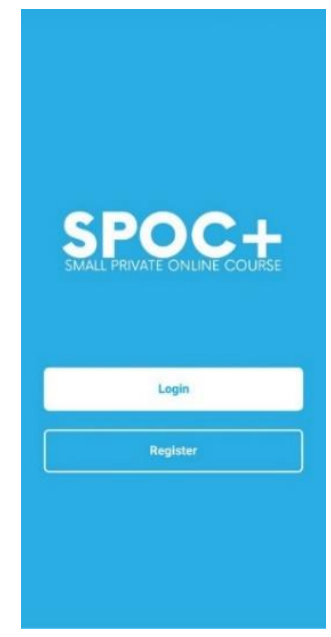

Figure 2. SPOC+ mobile interface

We have dedicated the web interface only for the administrator and teachers. The administrator plays the role of the traditional administrative service; he is in charge of defining access rights at different levels for teachers and learners. He will also be in charge of checking for the payments of registrations during the course for the learners.

In our system, we chose the project-based pedagogy invented by John Dewey (Dewey, 1986). The learning process organized by the teacher or a group of teachers to reach a predetermined target. According to Stephanie Bell, "Project-Based Learning (PBL) is a student-driven, teacher-facilitated approach to learning" (Bell, 2010).

The teacher will access with his login and password provided by the administrator, he would discover the list of learners with various information about them, including their names, dates of birth, current level, requested course, geographical location and time zones.

With his web interface, teacher will be able to associate the participants to the forums and define the topics to cover in his forums according to his teaching method and based on the needs of learners. Teacher is in charge of adding learners in different forums.

The mobile application is intended only for learners. They will be able to identify themselves using the login and password provided after acceptance of the administrator and pedagogical service. They will be able to participate in different forums that the teacher already gave access them. At any time, he will be able to be in contact with the teacher through the chat tool. The chat tool is the synchronous or asynchronous contact point between the learner and the teacher. In the chat tool and forums, the participants will be able to send any kind of document (text, video, sound, pdf, image, etc...).

We have named our solution SPOC+, its SPOC with a big plus. The choice of the learner's level based on the criteria set out by the CEFRL ${ }^{3}$, which our reference point for distinguishing the learner's knowledge. We propose that the learner has acquired the basics of the French language in writing, speaking and

\footnotetext{
${ }^{3}$ Common European Framework of Reference for Languages
} 
comprehension. This level will allow learners to understand the different parts of the software; and communicate with other learners and teachers; via forum or chat, to answer the questions and to participate in the social life of the class. The audience that is chosen in the concept of our software is an audience that has already acquired the B1 level and would like to start the B2.

Through SPOC+, all four necessary skills proposed for language acquisition including oral comprehension, written comprehension, oral production and written production; are offered to the learner.

Each level consists of several sessions, which are divided into several courses and each course composed of different lessons. The presentation of the content in lessons corresponds to a modular division. Each lesson corresponds to an object of study sufficiently limited to constitute a scientifically and pedagogically autonomous element and is therefore used when it is assembled or detached from the rest of the course. Not all lessons occupy the same volume and do not present the same difficulty. The amount of work time required by the student will not necessarily be the same from one lesson to the next. For each lesson, a set of activities offered to the student. The required time to read, listen, watch, and participate in each session should not exceed 70 minutes; the necessary videos are cut in 15 minutes maximum.

An information sheet is systematically attached to each lesson, giving useful information such as the title, summary, keywords, estimated working hours, date of the last update, objectives, prerequisites, and general advices on learning methods for the learner.

Maximum 25 learners can participate in each class. We have limited the number of learners per class to allow the teacher a personalized follow-up, which is one of the significant differences between the MOOC and the SPOC.

\section{CONCLUSION}

This article proposes SPOC+, as a new solution for mlearning, which integrated MIRTO and SPOC. Previous research studies have not proposed SPOC in language mobile learning. As we discussed in this article, today, SPOC is one of the solutions for language learning with mobile artifacts. Thus, SPOC+ demonstrates learning anytime, anywhere, sociable, on the mobile device, and with an educator. Our practical contribution tested with three users to analyze the intuitiveness of our solution. The theoretical contribution of this study is that a framework proposed for French language learners and should be tested in other languages.

Our main limitation is testing the solution in the real environment, within 25 learners from a non-French speaking country who have been pre-qualified, evaluating the level of satisfaction of the learners over four weeks of participation. For the future, we propose to extend the research from the basic level of French learners and reach other languages.

\section{REFERENCES}

Abdous, M., Camarena, M.M., Facer, B.R., 2009. MALL Technology: Use of Academic Podcasting in the Foreign Language Classroom. ReCALL 21, 76-95. https://doi.org/10.1017/S0958344009000020

Ahn, T. youn, Lee, S.-M., 2016. User experience of a mobile speaking application with automatic speech recognition for EFL learning: Speaking app with ASR. Br J Educ Technol 47, 778-786. https://doi.org/10.1111/bjet.12354

Allauzen, A., Bonneau-Maynard, H., 2008. Training and evaluation of POS taggers on the French MULTITAG corpus 5.

Antoniadis, G., 2010. De l'apport pertinent du TAL pour les systèmes d'ALAO : l'exemple du projet MIRTO, in: 2ème Congrès Mondial de Linguistique Française. Presented at the 2ème Congrès Mondial de Linguistique Française, EDP Sciences, La Nouvelle-Orléans, Etats-Unis, p. 150. https://doi.org/10.1051/cmlf/2010228

Antoniadis, G., Kraif, O., Lebarbé, T., Ponton, C., Echinard, S., 2005. Modélisation de l'intégration de ressources TAL pour l'apprentissage des langues : la plateforme MIRTO. alsic. https://doi.org/10.4000/alsic.376

Attewell, J., Savill-Smith, C., 2005. Mobile learning anytime everywhere: A book of papers from MLEARN 2004. Learning and Skills Development Agency.

Bell, S., 2010. Project-Based Learning for the 21st Century: Skills for the Future. The Clearing House: A Journal of Educational Strategies, Issues and Ideas 83, 39-43. https://doi.org/10.1080/00098650903505415

Chen, J., 2019. Exploration and Application of SPOC-based Belended Teaching Mode in Comprehensive English Course. J. Phys.: Conf. Ser. 1237, 022115. https://doi.org/10.1088/1742-6596/1237/2/022115 
Dejean, C., Fortun, M., Massot, C., Pottier, V., Poulard, F., Vernier, M., 2010. Un étiqueteur de rôles grammaticaux libre pour le français intégré à Apache UIMA.

Dewey, J., 1986. Experience and education, in: The Educational Forum. Taylor \& Francis, pp. 241-252.

Fox, A., 2013. From MOOCs to SPOCs. Commun. ACM 56, 38-40. https://doi.org/10.1145/2535918

Fox, A., Patterson, D., 2013. Software Engineering Curriculum Technology Transfer: 9.

Lei, M., 2019. Research on Hybrid Teaching Mode of Software Engineering Based on SPOC. J. Phys.: Conf. Ser. 1237, 052009. https://doi.org/10.1088/1742-6596/1237/5/052009

Li, M., Qi, X., Song, M., Li, Y., 2019. The Feasibility Study of Blended English Teaching Based on SPOC 329, 4.

Liu, P.-L., Chen, C.-J., 2015. Learning English through actions: a study of mobile-assisted language learning. Interactive Learning Environments 23, 158-171. https://doi.org/10.1080/10494820.2014.959976

Reynolds, B.L., Anderson, T.A.F., 2015. Extra-Dimensional In-Class Communications: Action Research Exploring Text Chat Support of Face-to-Face Writing. Computers and Composition 35, 52-64. https://doi.org/10.1016/j.compcom.2014.12.002

Rheingold, H., 2002. Smart Mobs: the next social revolution Cambridge. MA: Perseus.

Schmid, H., 1994. Probabilistic Part-of-Speech Tagging Using Decision Trees, Intl, in: Conference on New Methods in Language Processing. Manchester, UK.

Shadiev, R., Hwang, W.-Y., Huang, Y.-M., 2017. Review of research on mobile language learning in authentic environments. Computer Assisted Language Learning 30, 284-303. https://doi.org/10.1080/09588221.2017.1308383

Sharples, M., 2002. Disruptive devices: mobile technology for conversational learning. IJCEELL 12, 504. https://doi.org/10.1504/IJCEELL.2002.002148

Singh, S., 2006. Impact of color on marketing. Management Decision 44, 783-789. https://doi.org/10.1108/00251740610673332

Vavoula, G.N., Lefrere, P., O’Malley, C., Sharples, M., Taylor, J., 2004. Producing guidelines for learning, teaching and tutoring in a mobile environment, in: The 2nd IEEE International Workshop on Wireless and Mobile Technologies in Education, 2004. Proceedings. Presented at the The 2nd IEEE International Workshop on Wireless and Mobile Technologies in Education, 2004. Proceedings., pp. 173-176. https://doi.org/10.1109/WMTE.2004.1281378

Wu, T.-T., 2016. English Reading E-Book System Integrating Grouping and Guided Reading Mechanisms Based on the Analysis of Learning Portfolios. Journal of Internet Technology 17, 231-241.

Wu, T.-T., 2014. The use of a mobile assistant learning system for health education based on project-based learning. Comput Inform Nurs 32, 497-503. https://doi.org/10.1097/CIN.0000000000000089 